\title{
Thermal effects of an innovative green wall on building energy performance
}

\author{
R. Djedjig ${ }^{1, a}$, M. El Ganaoui ${ }^{1}$, R. Belarbi ${ }^{2}$ and R. Bennacer ${ }^{3}$ \\ 1 LERMAB, University of Lorraine, IUT de Longwy, 186 rue de Lorraine, 54400 Cosnes-et-Romain, France \\ 2 LaSIE, University of La Rochelle, Avenue Michel Crépeau, 17000 La rochelle, France \\ 3 LMT, ENS Cachan, 61 avenue du Président Wilson, 94235 Cachan, France
}

Received 16 February 2015, Accepted 18 February 2016

\begin{abstract}
Green walls and green roofs are innovative construction technologies involving the use environmentally friendly materials. In addition to their aesthetical and environmental benefits, green walls have significant thermal effects on buildings and heat islands within high-density urban areas. In this paper, we study the impact of an innovative green wall system on building energy performance. These green walls have specific composition and particular geometry that can lead to higher thermal performances and therefore more significant impact on building energy performance. The development, validation and prior integration of a hygrothermal green wall model in a transient building simulation tool make possible the assessment of the energy performance of buildings when covered by green walls. The used model was adapted to be the particular forms and composition of the studied green walls. In parallel, this type of green walls has been installed on a one tenth building mockup to be experimented. The aim of the experiment is to measure the thermal effects and to calibrate some parameters of the numerical model. The results highlight the thermal benefits of this kind of green walls in summer condition. They reduce annual energy demand of building up to $37 \%$ for hot climates.
\end{abstract}

Key words: Heat and moisture modelling / green wall / building energy simulation / experiment

\section{Introduction}

The research on energy performance of buildings and their environmental quality improvement has become indispensable for sustainable urban development. Green roofs and green facades, which consist on plant covering of external surfaces, have considerable potential to reduce building energy consumption. Several studies show various benefits associated with the use of these bio-based architectural elements in terms of energy saving [1-3], urban microclimate [4-6], stormwater management [7-9], sound insulation $[10,11]$, air pollution $[12,13]$ and social and psychological aspects [14-16].

Thermal effects of green roofs and green walls were the subject of some experimental studies. Most often, it has been to monitor green roofs or green façade installed residential or commercial buildings in order to compare reached temperatures or energy consumptions with or without the vegetated envelope part. Generally,

\footnotetext{
${ }^{a}$ Corresponding author:

rabah.djedjig@univ-lorraine.fr
}

collected data showed noticeable thermal benefits, especially for temperate climates $[2,17-19]$. Indeed, the thermal behavior of the vegetated wall is quite different from conventional walls made of common materials. The reason is that green roofs and green walls consist of plants substrate. The hygrothermal and radiative behavior of plants, which are living species, is variable over time and depending on meteorological conditions. Indeed, the type of the used plants must be adapted to the local climate. Growth conditions and seasonal cycles imply change in many thermal and radiative characteristics such as the leaf area index or the leaves color. Therefore, some biophysical phenomena, in particular evapotranspiration, are directly controlled by the plant life cycles.

Modeling the hygrothermal behavior of vegetated walls is quite complex but it is possible to simulate by accounting for the most influential heat and mass transfer phenomena. The heat transfer through the green wall is coupled to the water transfer in its different layers. Furthermore, the thermophysical parameters of the green walls layers are depend on the technology and the structure of the green wall. In fact, the kind of the drainage 


\section{Nomenclature}

\begin{tabular}{|c|c|c|}
\hline$d_{\mathrm{f}}$ & Average leaf thickness & $\mathrm{m}$ \\
\hline$D$ & Drainage & $\mathrm{kg} \cdot \mathrm{m}^{-2} \cdot \mathrm{s}^{-1}$ \\
\hline$E$ & Evapotranspiration & $\mathrm{kg} \cdot \mathrm{m}^{-2} \cdot \mathrm{s}^{-1}$ \\
\hline$F$ & Leaf area index & - \\
\hline$h$ & Height & $\mathrm{m}$ \\
\hline$H$ & Sensible heat flux & $\mathrm{W} . \mathrm{m}^{-2}$ \\
\hline$k$ & Thermal conductivity & $\mathrm{W} \cdot \mathrm{K}^{-1} \cdot \mathrm{s}^{-1}$ \\
\hline$l_{\mathrm{v}}$ & Latent heat of vaporization & ${\mathrm{J} . \mathrm{kg}^{-1}}^{-1}$ \\
\hline$L$ & Latent heat flux & $\mathrm{W} \cdot \mathrm{m}^{-2}$ \\
\hline$p_{\mathrm{v}}$ & Vapor pressure & $\mathrm{Pa}$ \\
\hline$P$ & Rainfall & $\mathrm{Pa}$ \\
\hline$r_{\mathrm{a}}$ & Aerodynamic resistance to sensible heat transfer & s.m ${ }^{-1}$ \\
\hline$r_{\mathrm{c}}$ & Resistance to heat flow from soil surface displacement height & s.m ${ }^{-1}$ \\
\hline$r_{\mathrm{sub}}$ & Substrate surface resistance to mass transfer & s.m ${ }^{-1}$ \\
\hline$r_{\mathrm{s}, \min }$ & Minimum leaf stomatal resistance & s.m $\mathrm{m}^{-1}$ \\
\hline$R_{\mathrm{n}}$ & Net radiation flux & $\mathrm{W} \cdot \mathrm{m}^{-2}$ \\
\hline$t$ & Time & $\mathrm{s}$ \\
\hline$T$ & Temperature & $\mathrm{K}$ \\
\hline$u$ & Wind speed & $\mathrm{m} . \mathrm{s}^{-1}$ \\
\hline$z$ & Altitude or depth & M \\
\hline \multicolumn{3}{|c|}{ Greek letters } \\
\hline$\gamma$ & Thermodynamic psychometric constant & $\mathrm{Pa} . \mathrm{K}^{-1}$ \\
\hline$\varepsilon$ & Emissivity & - \\
\hline$\rho_{\mathrm{s}}$ & Leaf shortwave reflectance & - \\
\hline$\rho_{\mathrm{g}}$ & Soil shortwave reflectance & - \\
\hline$\rho c_{\mathrm{p}}$ & Specific thermal capacity & $\mathrm{J} . \mathrm{m}^{-3} \cdot \mathrm{K}^{-1}$ \\
\hline$\sigma$ & Stefan-Boltzmann constant & $\mathrm{W} \cdot \mathrm{m}^{-2} \cdot \mathrm{K}^{-4}$ \\
\hline$\sigma_{\mathrm{f}}$ & Fractional vegetation coverage & - \\
\hline$\tau_{\mathrm{s}}$ & Leaf shortwave transmission & - \\
\hline$I_{\mathrm{s}}$ & Incident radiation on the horizontal & $\mathrm{W} \cdot \mathrm{m}^{-2}$ \\
\hline$\omega$ & Volumetric water content & - \\
\hline \multicolumn{3}{|c|}{ Subscripts } \\
\hline $\mathrm{a}$ & Air & \\
\hline $\mathrm{f}$ & Foliage & \\
\hline g & Ground (soil) surface & \\
\hline s & Solar/Shortwave & \\
\hline sat & Saturation value & \\
\hline sky & Sky/Longwave & \\
\hline $\mathrm{w}$ & Water & \\
\hline
\end{tabular}

layer used in green roofs, the use of certain type of substrate and the air layer often located between the latter and the building façade modify considerably the thermohydric behavior of vegetated envelopes [20,21].

This paper focuses on thermal impacts of innovative living walls Vertiss ${ }^{\mathrm{TM}}$. This study consists on modeling this specific green wall type by performing numerical simulations. The calculations are based on a thermohydric model established previously to simulate thermal indoor and outdoor thermal effects of vegetated envelopes [22-24]. This model considers heat and water balances on vegetated walls, it has been embedded into a building energy simulation program in a manner to evaluate vegetated buildings energy performance.

\section{Green wall model}

The green envelope model in this study has been programmed in python language and then it has been embedded into TRNSYS. Before embedding the model into the energy building simulation tool, the model was validated by measurements carried out on an experimental mockup located on the campus of the University of La Rochelle. The model considers two green envelope layers that are the leaves canopy (foliage) and the growing medium (substrate). The foliage acts as a semi-transparent screen whose shortwave radiation transmittance depends on the leaf area index. The substrate is a porous medium, of a given thickness, characterized by its maximum water 


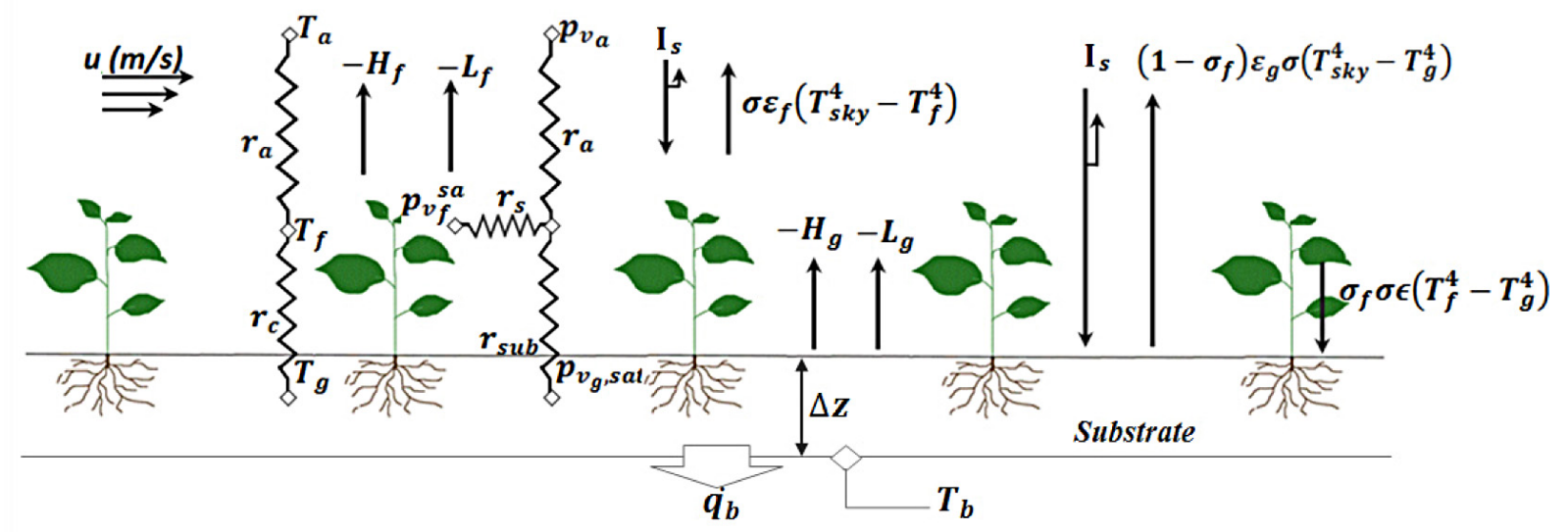

Fig. 1. Main modeled heat fluxes on a vegetated envelope module and corresponding heat and vapor transfer resistances.

capacity. The heat capacity and the thermal conductivity of the substrate vary according to the water content of this layer.

The model is based on energy and mass balances written for the foliage and the substrate layers. The energy balances account for the radiative, the sensible and for the latent heat transfer on the foliage and through the substrate (see Fig. 1). Convective heat fluxes are proportional to the temperature and partial vapor pressure gradients. Hence, these heat fluxes are expressed in terms of temperature or partial pressure vapor differences.

If we consider homogenous temperature within the foliage layer $\left(T_{\mathrm{f}}\right)$, we can write:

$$
\begin{aligned}
\left(\rho c_{\mathrm{p}}\right)_{\mathrm{f}} d_{\mathrm{f}} F \frac{\mathrm{d} T_{\mathrm{f}}}{\mathrm{d} t} & =R n_{\mathrm{f}}-H_{\mathrm{f}}-L_{\mathrm{f}} \\
H_{\mathrm{f}} & =F \frac{\left(\rho c_{\mathrm{p}}\right)_{\mathrm{a}}}{r_{\mathrm{a}}}\left(T_{\mathrm{f}}-T_{\mathrm{a}}\right) \\
L_{\mathrm{f}} & =F \frac{\left(\rho c_{\mathrm{p}}\right)_{\mathrm{a}}}{\gamma\left(r_{\mathrm{a}}+r_{\mathrm{s}}\right)}\left(p_{\mathrm{vf}, \mathrm{sat}}-p_{\mathrm{va}_{\mathrm{a}}}\right)
\end{aligned}
$$

where $R n_{\mathrm{f}}, H_{\mathrm{f}}$ and $L_{\mathrm{f}}$ (all in $\mathrm{W} . \mathrm{m}^{-2}$ ) are respectively the net radiative flux, the sensible heat flux and the latent heat flux. Here $F$ is the leaf area index, $\left(d_{\mathrm{f}}\right)$ is the mean leaf depth, $\left(\rho c_{\mathrm{p}}\right)$ is the volumetric heat capacity, $\left(r_{\mathrm{a}}\right)$ and $\left(r_{\mathrm{s}}\right)$ are respectively the aerodynamic and the stomatal resistances to heat and vapor transfer.

The Radiative flux $\left(R n_{\mathrm{f}}\right)$ is the sum of the absorbed solar irradiance $\left(R n_{\mathrm{f}, \mathrm{s}}\right)$ and the infrared radiation exchange with the external surface of the substrate, the sky and/or surrounding surfaces $\left(R n_{\mathrm{f}, \mathrm{IR}}\right)$. These terms are calculated as the following:

$$
\begin{aligned}
R n_{\mathrm{f}, \mathrm{s}}=\sigma_{\mathrm{f}} & {\left[\left(1-\tau_{\mathrm{f}, \mathrm{s}}-\rho_{\mathrm{f}, \mathrm{s}}\right)\left(1+\tau_{\mathrm{f}, \mathrm{s}} \rho_{\mathrm{g}, \mathrm{s}}\right)\right] I_{\mathrm{s}} } \\
R n_{\mathrm{f}, \mathrm{IR}}=\sigma_{\mathrm{f}} & {\left[\varepsilon_{\mathrm{f}} \sigma\left(T_{\mathrm{sky}}^{4}-T_{\mathrm{f}}^{4}\right)+\frac{1}{1 / \varepsilon_{\mathrm{f}}+1 / \varepsilon_{\mathrm{g}}-1} \sigma\right.} \\
& \left.\times\left(T_{\mathrm{g}}^{4}-T_{\mathrm{f}}^{4}\right)\right]
\end{aligned}
$$

Here $\left(\sigma_{\mathrm{f}}\right)$ is the fractional foliage coverage, $(\tau)$ and $(\rho)$ are respectively the solar transmittance and the solar reflectance. $(\varepsilon)$ is the thermal emissivity and $(\sigma)$ is the Stefan-Boltzmann constant. Subscripts (f) and (g) refer to the foliage and the substrate layers.

The heat and moisture transfer equations are coupled in the model, first by the thermophysical properties of the substrate that depend on the water content, this latter is calculated by water balance. Second, they are coupled by the boundary conditions on the external surface of the substrate and on the foliage. These latter involve the latent heat fluxes $\left(L_{\mathrm{f}}\right)$ and $\left(L_{\mathrm{g}}\right)$ are also used in the water content balance.

The dynamic thermal model of the substrate is based on the one dimensional heat equation. The boundary condition on the external surface heat fluxes is written in the same manner as for the foliage balance:

$$
\begin{aligned}
\frac{\partial}{\partial t}\left[\left(\rho c_{\mathrm{p}}\right)_{\mathrm{g}, \omega_{\mathrm{g}}} T\right]= & \frac{\partial}{\partial z}\left(k_{\omega_{\mathrm{g}}} \frac{\partial T}{\partial z}\right) \\
-\left.k_{\omega_{\mathrm{g}}} \frac{\partial T}{\partial z}\right|_{\mathrm{z}=0}= & R n_{\mathrm{g}}-H_{\mathrm{g}}-L_{\mathrm{g}} \\
R n_{\mathrm{g}}= & \left(1-\rho_{\mathrm{g}, \mathrm{s}}\right)\left(1-\sigma_{\mathrm{f}}\left(1-\tau_{\mathrm{f}, \mathrm{s}}\right)\right) I_{\mathrm{s}} \\
& +\sigma_{\mathrm{f}} \varepsilon_{\mathrm{fg}} \sigma\left(T_{\mathrm{f}}^{4}-T_{\mathrm{g}}^{4}\right)+\left(1-\sigma_{\mathrm{f}}\right) \varepsilon_{\mathrm{g}} \\
& \times \sigma\left(T_{\mathrm{sky}}^{4}-T_{\mathrm{g}}^{4}\right) \\
H_{\mathrm{g}}= & \frac{\left(\rho c_{\mathrm{p}}\right)_{\mathrm{a}}}{\left(r_{\mathrm{c}}+r_{\mathrm{a}}\right)}\left(T_{\mathrm{g}}-T_{\mathrm{a}}\right) \\
L_{\mathrm{g}}= & \frac{\left(\rho c_{\mathrm{p}}\right)_{\mathrm{a}}}{\gamma\left(r_{\mathrm{sub}}+r_{\mathrm{a}}\right)}\left(p_{\mathrm{v}_{\mathrm{g}, \mathrm{sat}}}-p_{\mathrm{v}_{\mathrm{a}}}\right)
\end{aligned}
$$

For more detail about the calculation of the different properties and resistances, see reference [22].

The water balance is given by Equation (3) which takes into account the water intake related to precipitation $(P)$, watering $(A)$, and water losses by drainage $(D)$ and evapotranspiration $€\left(\right.$ all in $\left.\mathrm{kg} \cdot \mathrm{m}^{-2} \cdot \mathrm{s}^{-1}\right)$. The amount $(E)$ of evapotranspiration is calculated according to latent heat fluxes that are $\left(L_{\mathrm{f}}\right)$ for plant transpiration and $\left(T_{\mathrm{g}}\right)$ 


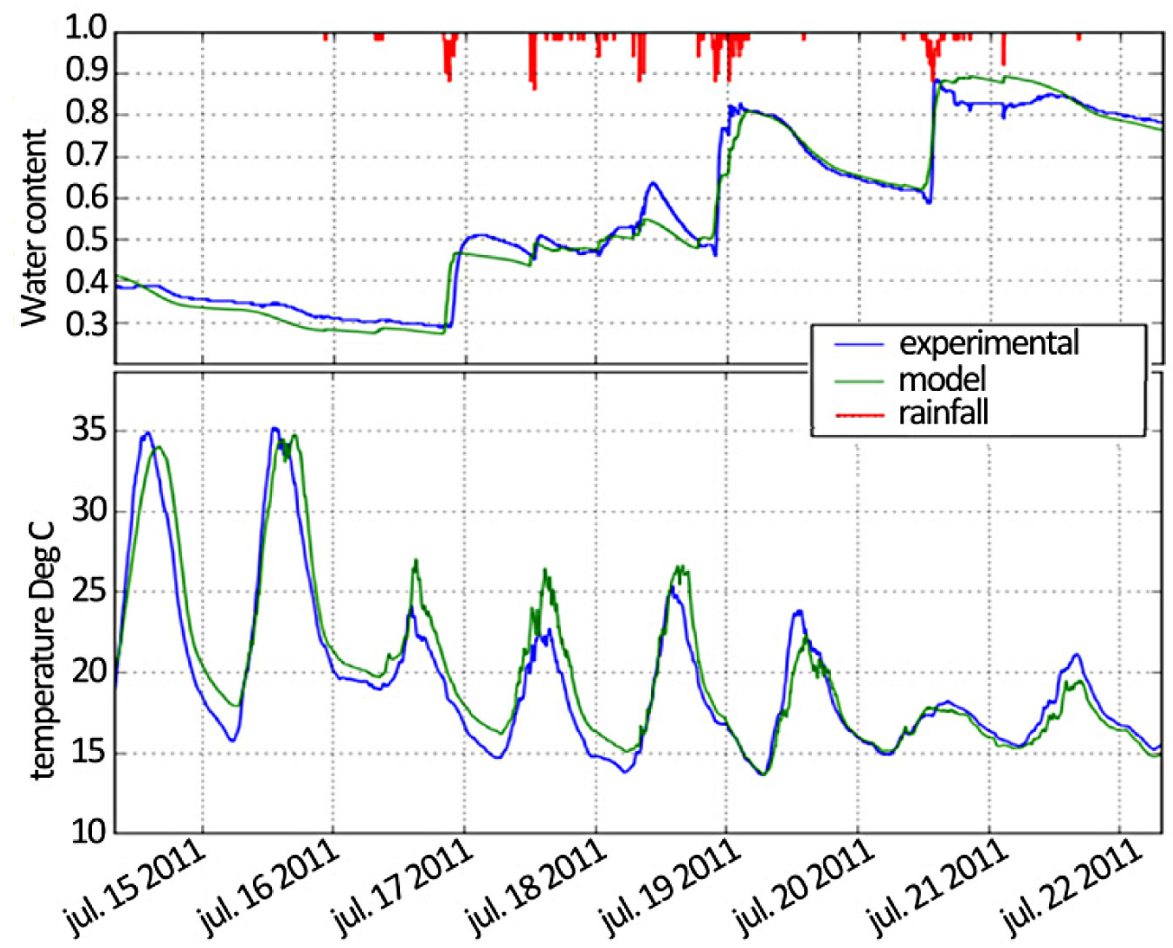

Fig. 2. Comparison between the numerical and the experimental temperature and water content results for a monitored green roof.

for direct evaporation. Hence, the water balance can be written as the following $\left(l_{\mathrm{v}}\left[\mathrm{J}_{\mathrm{kg}} \mathrm{kg}^{-1}\right]\right.$ is the latent heat of vaporization).

$$
\begin{aligned}
h_{\mathrm{g}} \frac{\partial \omega_{\mathrm{g}}}{\partial t} & =A+P-D-E \\
E & =\left(L_{\mathrm{f}}+L_{\mathrm{g}}\right) / l_{\mathrm{v}}
\end{aligned}
$$

The reliability of the model was verified by comparing numerical simulation results to measurements carried out an experimental mockup of green roofs set up at the University of La Rochelle. The performed comparisons showed good agreement between the numerical prediction and the observed thermo-hydrological behavior.

Figure 2 shows comparison model numerical results and experimental results for the two variables: external substrate surface temperature $\left(T_{\mathrm{g}}\right)$ and the station degree that correspond to the water content in the substrate. The data were collected during the third week of July 2011. This figure shows that the diurnal variations of surface temperature $\left(T_{\mathrm{g}}\right)$ are correctly predicted over a fairly long period with changeable weather condition variables. The rainfall recorded during this week led to lower the picks of temperatures achieved over time.

To simulate the building energy consumption of vegetated buildings, we use the building model available in the BES program TRNSYS. This building model is capable for simulating complex dynamic systems including buildings with their equipment, control strategies and occupants behavior. The green envelope model embedding into TRNSYS is undertaken by creating a new component type (see Fig. 3). When a new user component is created

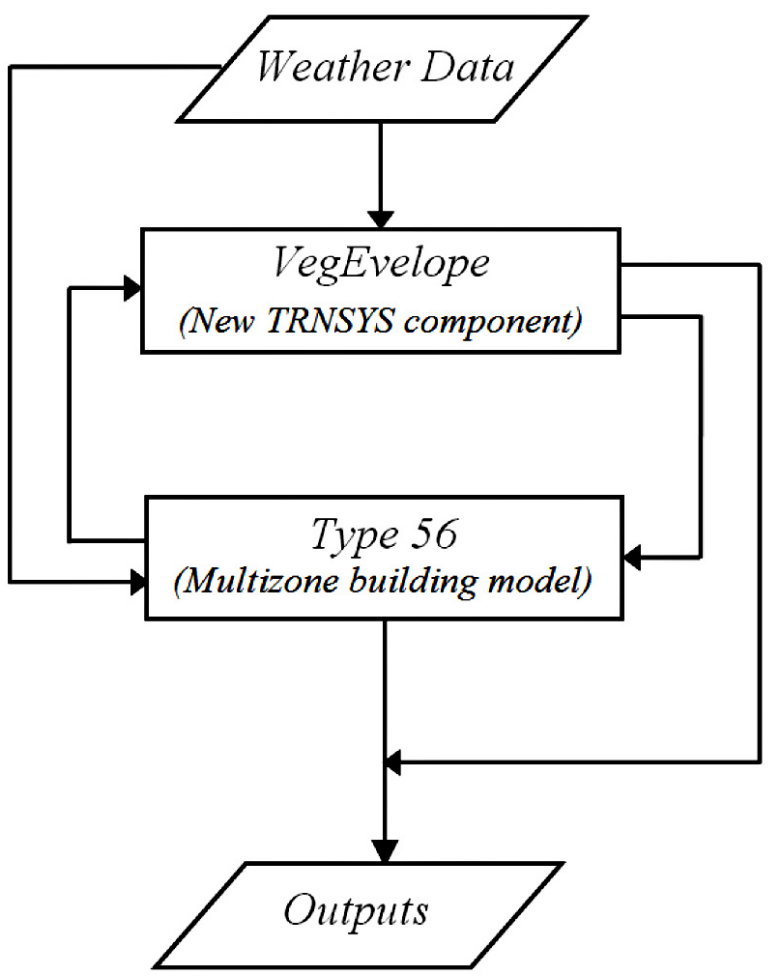

Fig. 3. Coupling the multizone building model with the new green envelope component in TRNSYS. 

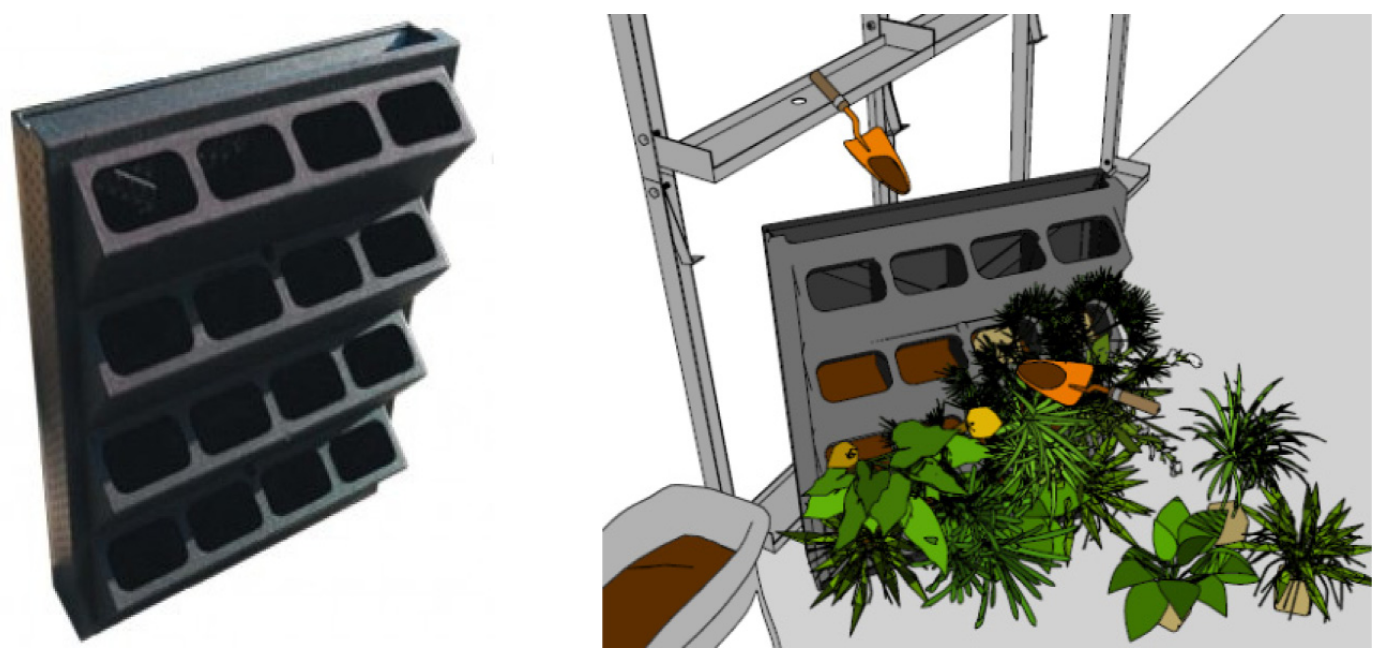

Fig. 4. Setting up Vertiss ${ }^{\mathrm{TM}}$ green walls.

in the software environment, this one can be used in the same way as any other standard TRNSYS component. Physically, green wall is adhered to an outer wall of the building. Numerically, it goes through a coupling to ensure the continuity of heat flux and temperature values at the interface for each time step of the simulation. See references $[23,25]$ for more details on the numerical development method.

\section{Description of the studied green walls}

The studied green wall (Vertiss ${ }^{\mathrm{TM}}$ ) consists of modular panels made of foamed propylene. The green walls are set up by attaching the panels on a galvanized metal grid and then to fill them with a specific substrate (see Fig. 4). The substrate is made to meet the settling constraints while still allowing a good root development. It consists of $70 \%$ mineral matter (pozzolana, expanded clay balls...) and $30 \%$ of organic matter (garden peat, compost...) and specific water retention agents.

The benefits of Vertiss ${ }^{\mathrm{TM}}$ green walls are manifold. In addition to its easy installation, it can be mounted and then taken apart unlike some other green walls. In addition, the vegetation is planted vertically in the green wall modules and vertical position is better to ensure good health. Indeed, the proper weight of plants is better supported by stems and roots in this position.

To model the thermohydric behavior of this kind of green wall, certain geometric and structural features should be taken into account because they affect directly the heat exchange on the facade. Indeed, this green wall is composed of various material layers which lead to different hygrothermal behavior. Starting from the building facade, layers to be considered in thermal modelling are (see Fig. 5a):

1. Air layer of $2-3 \mathrm{~cm}$ thickness between the building facade and back of the modular panel.
2. High density expanded polypropylene layer. It is a part of the modular panel and gives additional thermal insulation to building wall.

3. Substrate layer with an average of $10 \mathrm{~cm}$ depth.

4. Panel/substrate external surface with different tilt depending on whether it is the substrate or polypropylene area. When the leaf area index is small, tilted surfaces affect the solar radiation trapping not to mention the different radiative properties on this part. For high values of the leaf area index, mean values may be considered in overall thermal modelling; this is the case of the present study. Indeed, we consider that the leaf area index on the green wall is $F=4$.

5. The leaf canopy characterized by the leaf area index $F$ and the fractional foliage coverage $\sigma_{\mathrm{f}}$.

To take into account the specificities of this type of green walls, the green wall/building models have been adapted. Coupling the green wall component with the multizone building model of Trnsys was carried out in a way to consider the non-ventilated air layer and the adjacent polypropylene layer (layers \#1 and \#2 in Fig. 5). Thus, two layers with the same thermal properties were added to the east and west original walls in Type 56 of Trnsys. Furthermore, an average thickness of the substrate was considered to account for its variation. In addition, the thermal conductivity of the substrate layer has been adjusted to account for the polypropylene that covers a part of it. Finally, the radiative properties of the outer surface were averaged and the resistance to direct evaporation (rsub) was increased.

Parallel to the modelling approach, a green wall was set up recently at the University of La Rochelle in order to be studied in real weather conditions (see Fig. 6). Actually, the green wall is monitored on a reduced scale mockup of building. Data collected on this mockup will make possible analyzing the thermohydric behavior of the green wall in connection with weather data collected in situ. In addition the same experimental mockup was used to study another kind of green walls which use sphagnum moss as growing medium $[4,26]$. Hence, this experimental 


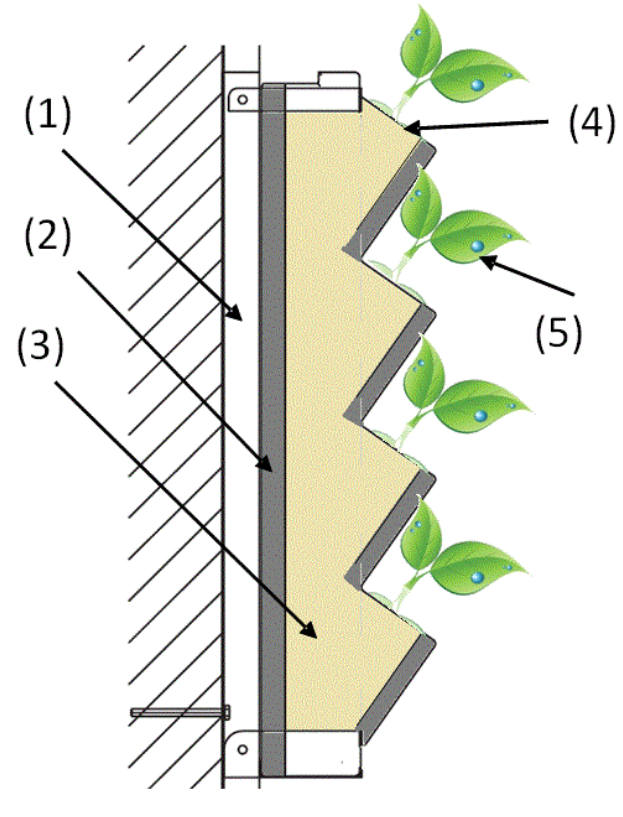

(a) Considered parts in
Vertiss ${ }^{\mathrm{TM}}$ green wall modeling

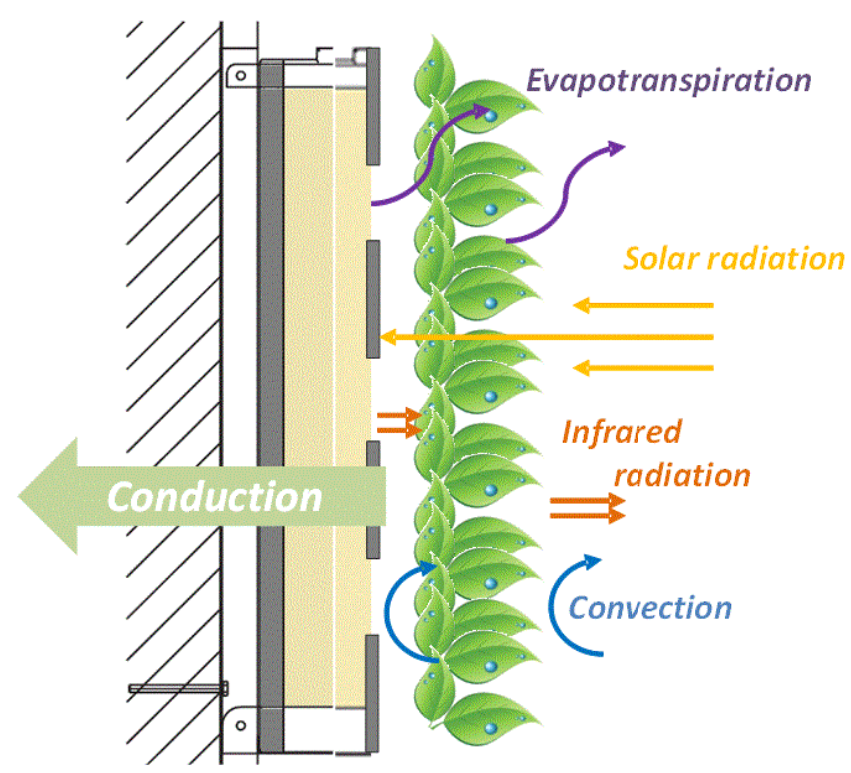

(b) 1D Equivalent thermal model

Fig. 5. Considered parts in Vertiss ${ }^{\mathrm{TM}}$ green wall modeling. (a) Considered parts in Vertiss ${ }^{\mathrm{TM}}$ green wall modeling. (b) 1D Equivalent thermal model.

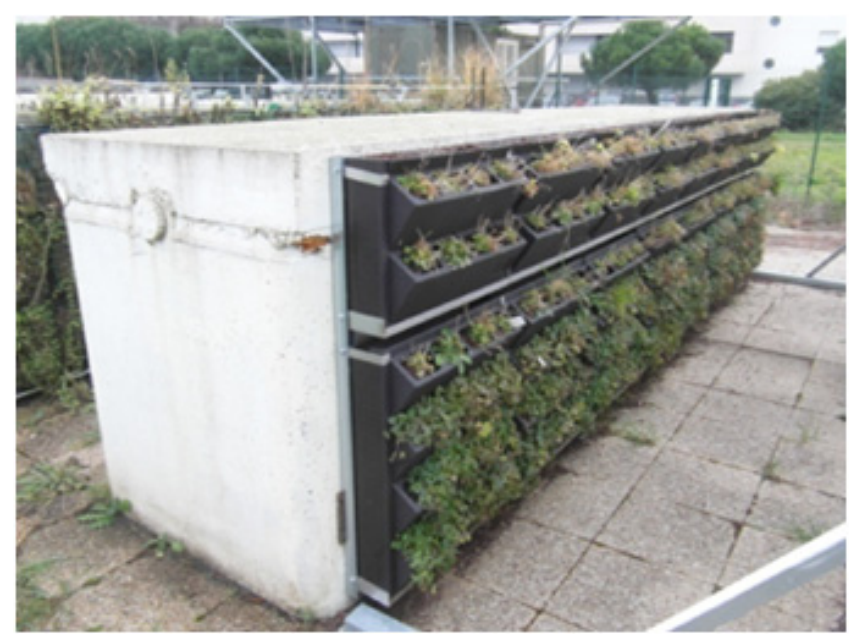

Fig. 6. "Vertiss"TM" Green wall monitoring at the University of La Rochelle.

approach will make possible to compare the two green wall technologies on the same building test.

\section{Results and discussion}

In this part, the green wall model embedded into TRNSYS is used to evaluate the thermal impact of this kind of green walls on buildings energy performance. The case study is a three-story building whose walls are made of $20 \mathrm{~cm}$ cinder block and the roof and ceilings made of $12 \mathrm{~cm}$ concrete. The building envelope is has inner insulation of $5 \mathrm{~cm}$ thick. The east and the west façade have glazing surfaces that represents $20 \%$ of the floor area. No internal gains are considered. The infiltration rate is set at $0.6 \mathrm{ACH}$. The albedo of reference facades is set to 0.5. To evaluate the energy effects of Vertiss ${ }^{\mathrm{TM}}$ green walls on this building, numerical studies have been conducted for this building with and without the use of the green wall module. So, for vegetated building case, both east and west facades are vegetated. The green wall substrate depth is $10 \mathrm{~cm}$ and its saturation ratio is fixed at $75 \%$. The vegetation coverage ratio is set at 1 and the leaf area index is set at 4 . Standard weather data of two different climates are used. The first is the La Rochelle climate and the second is Casablanca weather data.

Annual dynamic thermal simulations were performed for the studied building for both climates. The cooling system operates from May to September and the heating system is turned on from October to April. The cooling temperature is set at 26.C and the heating temperature is set at 19.C during day and 15.C during night. The calculated cooling and heating loads are compared for the reference building and for the same building covered with the green walls (see Figs. 7 and 8).

In summer, the green walls tested on the east and west facades of the building reduce the cooling load in both studied climates (see Fig. 8). This energy demand decrease is proportional to the cooling load of the reference building. This is true for La Rochelle and for Casablanca: at La Rochelle, the cooling load decreases from 7.8 to $2.5 \mathrm{kWh} . \mathrm{m}^{-2}$ when at Casablanca it decreases from 17.6 to $7.4 \mathrm{kWh} . \mathrm{m}^{-2}$. In winter, thermal effects are less clear. We even get a slight increase in the heating load for the 


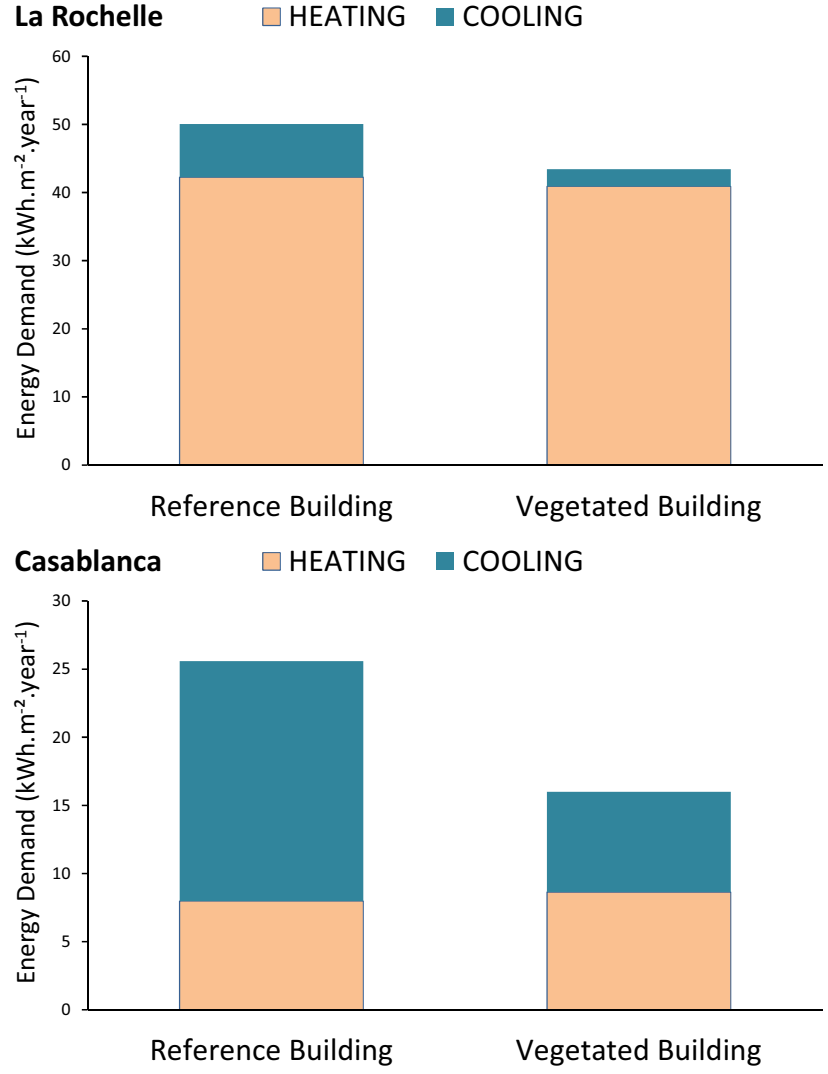

Fig. 7. Comparison between annual thermal loads for the reference building and for the vegetated building in La Rochelle (France) and Casablanca (Morocco).

building located in Casablanca. That being said, the overall thermal load remains obvious, especially when the cooling load is very important. This is the case of the building located in Casablanca where the annual energy demand was reduced by $37 \%$ thanks to the green walls.

\section{Conclusion}

In this paper we have adapted the green wall model integrated previously into TRNSYS to simulate the thermal behavior of an innovative green wall. To assess the impact on building energy performance of this kind of green walls, two case studies with and without vegetated east and west facade have been studied for two different climates. It has been found that the green wall impact is more significant for hot climates since it reduces substantially the cooling loads but less the heating loads. Future work is to refine thermal modeling of this kind of green walls and to compare the numerical results with experimental data being collected. Also, sensitivity studies will be conducted to determine the importance of different parameters in order to propose a reduced thermal model.

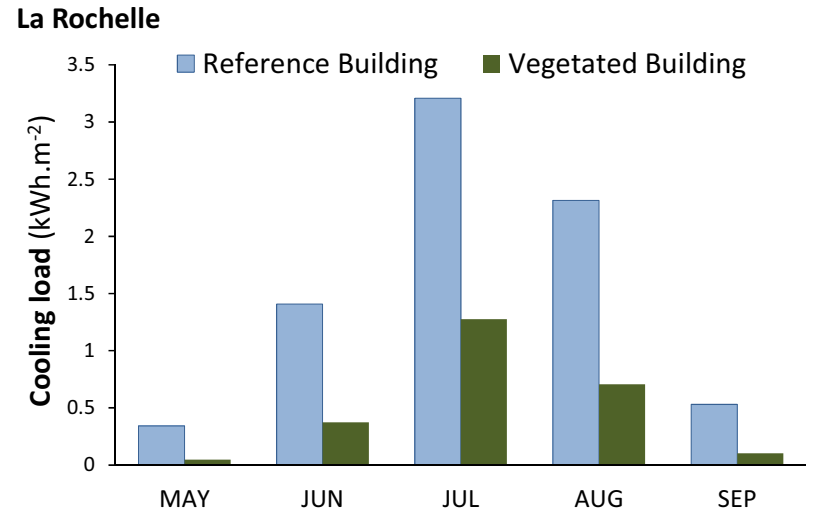

Casablanca

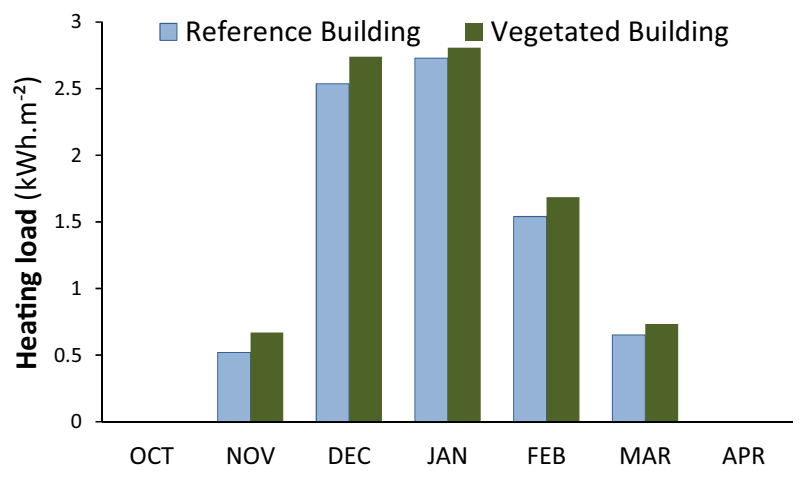

La Rochelle

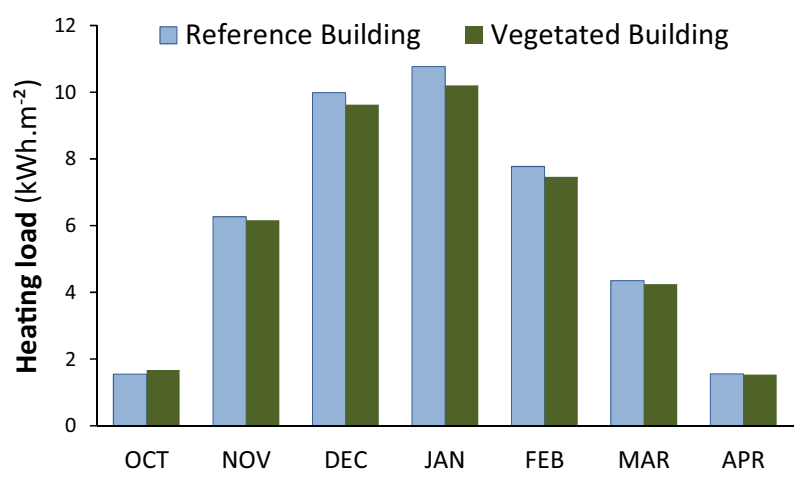

Casablanca

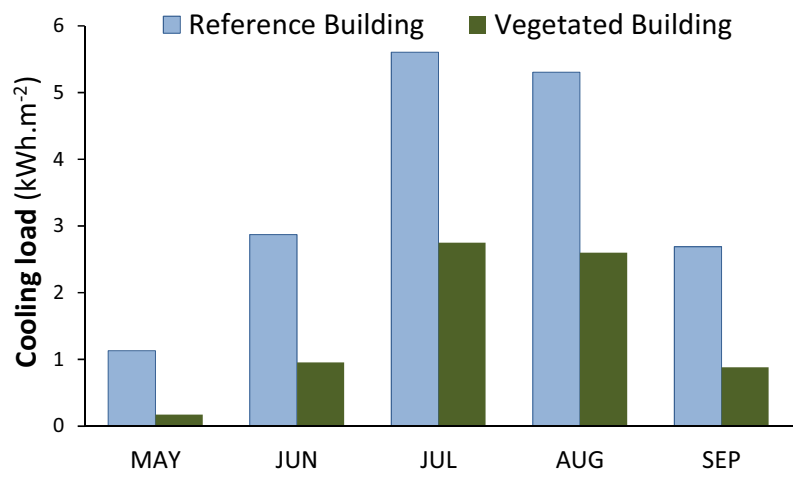

Fig. 8. Comparison between cooling and the heating thermal loads for the reference building and for the vegetated building in La Rochelle (France) and in Casablanca (Morocco). 


\section{References}

[1] M. Santamouris, C. Pavlou, P. Doukas, G. Mihalakakou, A. Synnefa, A. Hatzibiros, et al., Investigating and analysing the energy and environmental performance of an experimental green roof system installed in a nursery school building in Athens, Greece, Energy 32 (2007) $1781-1788$

[2] R. Fioretti, A. Palla, L.G. Lanza, P. Principi, Green roof energy and water related performance in the Mediterranean climate, Building Environ. 45 (2010) 1890-1904

[3] I. Jaffal, S.-E. Ouldboukhitine, R. Belarbi, A comprehensive study of the impact of green roofs on building energy performance, Renew. Energy 43 (2012) 157-164

[4] R. Djedjig, E. Bozonnet, R. Belarbi, Experimental study of the urban microclimate mitigation potential of green roofs and green walls in street canyons, Int. J. LowCarbon Tech. 10 (2015) 34-44

[5] K.R. Smith, P.J. Roebber, Green Roof Mitigation Potential for a Proxy Future Climate Scenario in Chicago, Illinois, J. Appl. Meteorol. Climatol. 50 (2011) 507-522

[6] E. Ng, L. Chen, Y. Wang, C. Yuan, A study on the cooling effects of greening in a high-density city: An experience from Hong Kong, Building Environ. 47 (2012) 256-271

[7] J. Mentens, D. Raes, M. Hermy, Green roofs as a tool for solving the rainwater runoff problem in the urbanized 21st century?, Landscape and Urban Planning 77 (2006) $217-226$

[8] J. Czemiel Berndtsson, Green roof performance towards management of runoff water quantity and quality: A review, Ecological Eng. 36 (2010) 351-360

[9] J.C. Berndtsson, L. Bengtsson, K. Jinno, Runoff water quality from intensive and extensive vegetated roofs, Ecological Eng. 35 (2009) 369-380

[10] T. Van Renterghem, D. Botteldooren, Reducing the acoustical façade load from road traffic with green roofs, Building Environ. 44 (2009) 1081-1087

[11] T. Van Renterghem, D. Botteldooren, Numerical evaluation of sound propagating over green roofs, J. Sound Vib. 317 (2008) 781-799

[12] M. Thoennessen, Elementdynamik in fassadenbegrünendem Wilden Wein, Kölner Geograph, Arbeiten Heft. 78 (2002) 1-110

[13] J. Yang, Q. Yu, P. Gong, Quantifying air pollution removal by green roofs in Chicago, Atmospheric Environ. 42 (2008) 7266-7273

[14] J. Raffan, La nature nourricière: une étude du potentiel d'apprentissage dans les cours d'école., Evergreen, Toronto, 2002

[15] E.V. White, B. Gatersleben, Greenery on residential buildings: Does it affect preferences and perceptions of beauty?, J. Environ. Psychology 31 (2011) 89-98
[16] A.E. Van Den Berg, T. Hartig, H. Staats, Preference for Nature in Urbanized Societies: Stress, Restoration, and the Pursuit of Sustainability, J. Social Issues. 63 (2007) $79-96$

[17] N.H. Wong, Y. Chen, C.L. Ong, A. Sia, Investigation of thermal benefits of rooftop garden in the tropical environment, Building Environ. 38 (2003) 261-270

[18] K. Liu, Engineering performance of rooftop gardens through field evaluation, in: RCI 18th International Convention and Trade Show (Tampa, Florida, 3/13/2003), 2003: pp. 1-15. http://archive.nrc-cnrc. gc.ca/obj/irc/doc/pubs/nrcc46294/nrcc46294.pdf (accessed July 4, 2013)

[19] A. Teemusk, Ü. Mander, Temperature regime of planted roofs compared with conventional roofing systems, Ecol. Eng. 36 (2010) 91-95

[20] C.Y. Jim, S.W. Tsang, Modeling the heat diffusion process in the abiotic layers of green roofs, Energy Buildings 43 (2011) 1341-1350

[21] K. Perini, M. Ottelé, A.L.A. Fraaij, E.M. Haas, R. Raiteri, Vertical greening systems and the effect on air flow and temperature on the building envelope, Building Environ. 46 (2011) 2287-2294

[22] R. Djedjig, S.-E. Ouldboukhitine, R. Belarbi, E. Bozonnet, Development and validation of a coupled heat and mass transfer model for green roofs, Int. Commun. Heat Mass Transfer 39 (2012) 752-761

[23] R. Djedjig, E. Bozonnet, R. Belarbi, Analysis of thermal effects of vegetated envelopes: Integration of a validated model in a building energy simulation program, Energy Buildings 86 (2015) 93-103

[24] R. Djedjig, E. Bozonnet, R. Belarbi, A hygrothermal model of green walls interactions in street canyons, numerical developement and experimental comparison, in: Proceedings of IC2UHI 2014:Third International Conference on Countermeasures to Urban Heat Island, Venice, 2014, pp. 1540-1551

[25] R. Djedjig, E. Bozonnet, R. Belarbi, Integration of a green envelope model in a transient building simulation program and experimental comparison, in: Proceedings of BS 2013: 13th Conference of the International Building Performance Simulation Association, 2013, pp. 47-53

[26] R. Djedjig, R. Belarbi, E. Bozonnet, Experimental Study of a Green Wall System Effects in Urban Canyon Scene, in: Proceedings of CLIMA 2013: 11th REHVA World Congress and the 8th International Conference on Indoor Air, Prague, Czech Republic, 2013. 